\title{
The Effect of Online education after COVID-19 : Focusing on Personal and Social Motivation
}

\author{
HongKun Chin, Professor, School of Communication Advertising Public Relationship Major, Kookmin \\ University, 77, Jeongneung-ro, Seongbuk-gu, Seoul 02707 Korea, chin1101@kookmin.ac.kr \\ *Corresponding Author
}

\begin{abstract}
The purpose of this study is to investigate the impact of the rapid transition to online classes due to the COVID-19 epidemic on learning effectiveness by a comparative analysis on learning effectiveness considering different types of offline and online classes for the same subject.

As a result, the interaction between personal motivation and class type is not significant. On the other hand, the interaction between social motivation and class type is significant and overall online class increases engagement with educational issues. In particular, the group with low social motivation showed greater change than the group with high social motivation, so online education seems to be more effective in the group with low social motivation. It means that by stimulating students' social motivation rather than personal motivation, the effectiveness of online education can be enhanced, and it can lead to education outcomes - behavioral changes and attitudes of learners.

In order to revitalize social motivation in the intensely personal space of online, it is necessary to activate social communication methods such as SNS, and development of interpersonal issues and learning materials would be more efficient. In order to derive more specific results, it is necessary to measure the level of prior knowledge and involvement of the participants in class, and to comprehensively investigate and analyze the state of learners before and after class through more variables. Finally, in order to increase the reliability of the research results, it is necessary to clearly prove it through the establishment of a structural model.
\end{abstract}

Keywords: After COVID-19, engagement, offline education, online education, Personal motivation, Social motivation, unification education, ANOVA

$\begin{array}{lll}\text { Received: 07.12.2020 } & \text { Accepted: 13.01.2021 } & \text { Published: 08.02.2021 }\end{array}$

\section{INTRODUCTION}

The global COVID-19 pandemic has made offline classes overall difficult. Not only elementary, middle, and high school education, but even university practical education is being replaced by online education. The transition from offline classes to online classes was made rapidly. This study wondered how the dramatic changes are having an impact on the students' learning effect. Previous researches described that online education identified passive learners as active and positive learners. In other words, in the previous offline education, learning is viewed as a listening-centered learning attitude, whereas in online education, system access, search, and opinion expression are viewed as active and positive learning attitudes.

In addition, online education because of reduced temporal and spatial constraints, provides accessibility, ease of use, economics, and efficiency, and is being evaluated as an optimized method as a future education support system thanks to the development of IT technology, and provides various learning opportunities to more leaners thanks to its features such as openness and timeliness.

With the development of IT technology, online education is being revitalized. Is the driving force behind online education? Or is it a motivation? The emergence of interactive media such as SNS media has a great influence on not only content consumption but also media education. Consumers who search for and use a lot of online information to meet their needs are beginning to recognize the value of online experiences. Unlike offline education, online education has a strong tendency to participate in voluntary learning, so an approach that takes this into account is necessary. In particular, it will be possible to induce more effective learning by analyzing learners' motivations to learn according to their voluntary willingness to learn.

Most of the previous researches on online education focused on technical aspects of education represented by networks and interactivity. The effectiveness of online education was verified based on the technology adoption model and the innovation resistance model. Of course, an understanding of the characteristics of online media is essential, and it has the characteristics that interactive communication 
is possible and convergence through combination with other digital devices is excellent. Considering this differentiation, it can be said that previous researches are also very important. However, as a factor that causes media consumption, the motivation to use it is as important as the ability to utilize the technical characteristics of the media. In particular, it is not an exaggeration to say that learning in online education is influenced by the degree of autonomous and independent learning efforts of learners. Therefore, the learner's self-regulated learning ability and motivation can act as an important factor in the success or failure of learning.

However, although the development of IT technology creates an environment that can lead to more active class participation, it is necessary to go through several stages before more active class participation leads to learning outcomes associated with behavioral change. This study attempted to examine the role of motivation to elicit more active attitudes of consumers.

[1]said that the purpose of motivational theory is to predict behavior, and that motivation is related to the force that influences behavior and choice of behavior internally and externally. Motivations that cause behavior can be classified into personal and social motivations according to the learner's reason and goal. Personal motivation is defined as acting because the behavior itself interests or enjoys the individual, and social motivation is a motivation such as recognizing a response to a reward or expecting a reward from another person. Therefore, social motivation is related to an individual's social psychology expected according to the behavioral outcome.

\section{Theory and formula}

Motivation is a force that promotes behavior, related to individual decision making and direction[2]. [3] distinguished motivations that influence decision-making into two types: personal motivation and social motivation. Personal motivation is an intrinsic tendency related to interest or learning. Social motivation is utilized to enrich conversation topics and activate relationships with others [4].

The main point of view so far has been that consumers use a specific product or service due to personal motivations such as interest, joy, and satisfaction that arise from the consumption behavior itself when purchasing a product or service [5]. Recently, people prefer to share common experiences [6] and the more people talk about a particular product or service, the more it will affect others [7]. It means that social motivation can also influence individual choices and actions, as well as the tendency to establish themselves as members of society by sharing specific experiences. It was proved that personal motivation and social motivation influence consumer choice or online information selection as antecedent factors for consumption. In the study of Tao [5], it can be seen that the two motives are influenced by the individual personality, which has an effect on the experience.

Online education has a combination of two characteristics: mass media function that provides contents by using IT technology and various devices, and personal media that can be used selectively and actively according to the needs of users. Therefore, when learners participate in online education, there is a possibility that both personal and social motivations exert influence.

It is assumed that motivation also affects consumer engagement and high-relationship engagement. Engagement can be defined to the extent that audiences exposed to message information or advertisements understand, immerse, and focus on the information. [8] found that engagement is a precondition of involvement. It is used in various ways such as media engagement, advertisement engagement, brand engagement, etc. to the extent of understanding the information acquired through the media through the amount of immersion in the media [9]. Therefore, the motivation to access and consume media can increase immersion in online education, which will ultimately lead to increased engagement[10]. Consequently, the following hypothesis was established.

Hypothesis 1: There is a significant interaction between class type and engagement based on personal motivation

Hypothesis 2: There is a significant interaction between class type and engagement based on social motivation

\section{Experimental setup}

An online survey was conducted for 105 students who took offline classes in the pre COVID-19 and 244 students who took online classes in the post COVID-19, a total of 349 students. The subject of both classes are same on the unification of liberal arts. All responses were used as analysis data. The purpose of this study is to find out the effect of interaction on unification-related engagement. For the purpose, a two-way ANOVA analysis is applied to verify the effectiveness of interaction on the engagement for unification by classifying it into the difference between the level of personal motivation and the level of social motivation.

In order to measure personal and social motivations, the motivation scale presented by [5] is 
applied. [5] classified motivations into personal and social motivations, and clarified that there are differences in the role of motivation according to the class type. Therefore, this study judged personal and social motivations as dependent variables of engagement on unification subjects of on-off education, and those motivations were used to measure differences in educational effectiveness. The numbers of questions for personal motivation and social motivation are 4, respectively, and all were measured on a 5point Likert scale. motivation scale for personal motivation include follows: 'unification-related content stimulates me', 'gives joy', 'enriches my heart', and 'improves my life'. motivation scale for social motivations include follows: 'It will enrich my conversation topic', 'I will improve interpersonal relations', 'Because I can evaluate me well', and 'A social trend is expected and used.' As for the reliability of the measurement variables used in this study, Cronbach $\alpha=.90$ for personal motivation and Cronbach $\alpha=.89$ for social motivation were judged to be appropriate for use in analysis.

In this study, engagement variables are evaluated on a 5-point Likert scale on 7 questions that are modified the questions suggested by [11] which are related to interest, benefit, and flow/immersion. Measurement items includes follow questions: 'unification-related content caught my attention', 'I felt a strong desire to view unification-related content', 'I didn't know that time was passing while watching unification-related content', 'I have been immersed in the image of unification-related content. ', 'I have an urge to see unification-related content and visit related regions', 'unification-related content provides a variety of information', and 'unification-related content information is beneficial to me.' The reliability between the measurement variables by Cronbach $\alpha$ was adequate 0.90 .

\section{Results and Discussion}

When classifying groups according to the high and low levels of personal and social motivations, the median value was used, and the median value of personal motivation was 3.00 and the median value of social motivation was 2.75 . As a result, the descriptive statistics on the engagement for unification according to class type and the high and low levels of personal motivation were as follows: 78 students in the offline and low personal motivation group ( $\mathrm{M}=2.74, \mathrm{SD}=.73), 27$ students in the offline and high personal motivation group( $\mathrm{M}=3.19, \mathrm{SD}=.92), 161$ students in the online and low personal motivation $\operatorname{group}(\mathrm{M}=3.02, \mathrm{SD}=.79)$, and 83 students in the online and personal motivation group( $\mathrm{M}=3.63, \mathrm{SD}=.58)$.

Table 1. Engagement according to personal motivation by class type Two-way ANOVA ( $n=349)$

\begin{tabular}{|c|c|c|c|c|}
\hline Source & S.S & d.f. & MS & F-value \\
\hline \multicolumn{5}{|l|}{ Main Effect } \\
\hline $\begin{array}{r}\text { Class Type } \\
\text { (offline vs online) }\end{array}$ & .78 & 1 & .78 & $14.14^{\star}$ \\
\hline $\begin{array}{r}\text { Personal Motivation } \\
\text { (Low vs High) }\end{array}$ & 16.40 & 1 & 16.40 & $29.42^{*}$ \\
\hline \multicolumn{5}{|l|}{ Interaction Effect } \\
\hline $\begin{array}{r}\text { Class Typex Personal } \\
\text { Motivation }\end{array}$ & .37 & 1 & .37 & .41 \\
\hline Error & 192.37 & 345 & .55 & \\
\hline Total & 3627.91 & 349 & & \\
\hline
\end{tabular}

Note: $p<.05^{*}$

Based on the results, A Two-way ANOVA was conducted to examine the effect of interaction between two independent variables. As a result shown in $<$ Table $1>$, the interaction between class type and personal motivation was not significant. However, there was a primary effect according to the class type and personal motivation. Therefore, $<$ Hypothesis $1>$ was rejected.

Next, the descriptive statistics on the engagement for unification according to class type and the high and low levels of social motivation were as follows: 51 students in the offline and low social motivation group( $\mathrm{M}=3.14$, S.D.=.61), 127 students in the online and low social motivation group( $\mathrm{M}=3.12$, S.D.=.97), and 117 students in the online and high social motivation group(M=3.33, S.D.=.49). Based on the results, a two-way ANOVA was conducted to investigate the interaction effect between the two independent variables. The results are shown in $<$ Table $2>$. 
Table 2. Engagement according to social motivation by class type Two-way ANOVA (n=349)

\begin{tabular}{|c|c|c|c|c|}
\hline Source & s.S & d.f. & MS & F-value \\
\hline \multicolumn{5}{|l|}{ Main Effect } \\
\hline $\begin{array}{r}\text { Class Type } \\
\text { (offline vs online) }\end{array}$ & 10.63 & 1 & 10.63 & $17.78^{\star}$ \\
\hline $\begin{array}{r}\text { Social Motivation } \\
\text { (Low vs High) }\end{array}$ & 11.51 & 1 & 11.51 & $19.24^{*}$ \\
\hline \multicolumn{5}{|l|}{ Interaction Effect } \\
\hline Class Type $\times$ Socia Motivation & 2.55 & 1 & 2.55 & $4.26^{\star}$ \\
\hline Error & 206.40 & 345 & .59 & \\
\hline Total & 3613.53 & 349 & & \\
\hline
\end{tabular}

Note: $p<.05^{*}$

As a result shown in $<$ Table $2>$, the interaction between class type and social motivation was significant $(\mathrm{F}=4.26$, d.f. $=1, \mathrm{p}<.05)$. Therefore, $<$ Hypothesis $2>$ was supported. A univariate flow up independent t-test was conducted for a more detailed analysis of these interaction effects. First, a group with low social motivation who participated in online class(M=3.12 S.D.=.97) had higher engagement with unification than who participated in offline class(M=2.55 S.D.=.88). The result is statistically significant $(\mathrm{t}=-3.61$, d.f. $=176, \mathrm{p}<.05)$. In addition, a group with high social motivation who participated in online class(M=3.33 S.D.=.49) showed higher engagement results $(t==-2.21$, d.f. $=169, p<.05)$ than who participated in offline class (M=3.14 S.D.=.61). The result is statistically significant. From these results, it was found that groups with low social motivation are more effective in online education. The statistic results are summarized in a chart, as shown in <Figure $1>$.

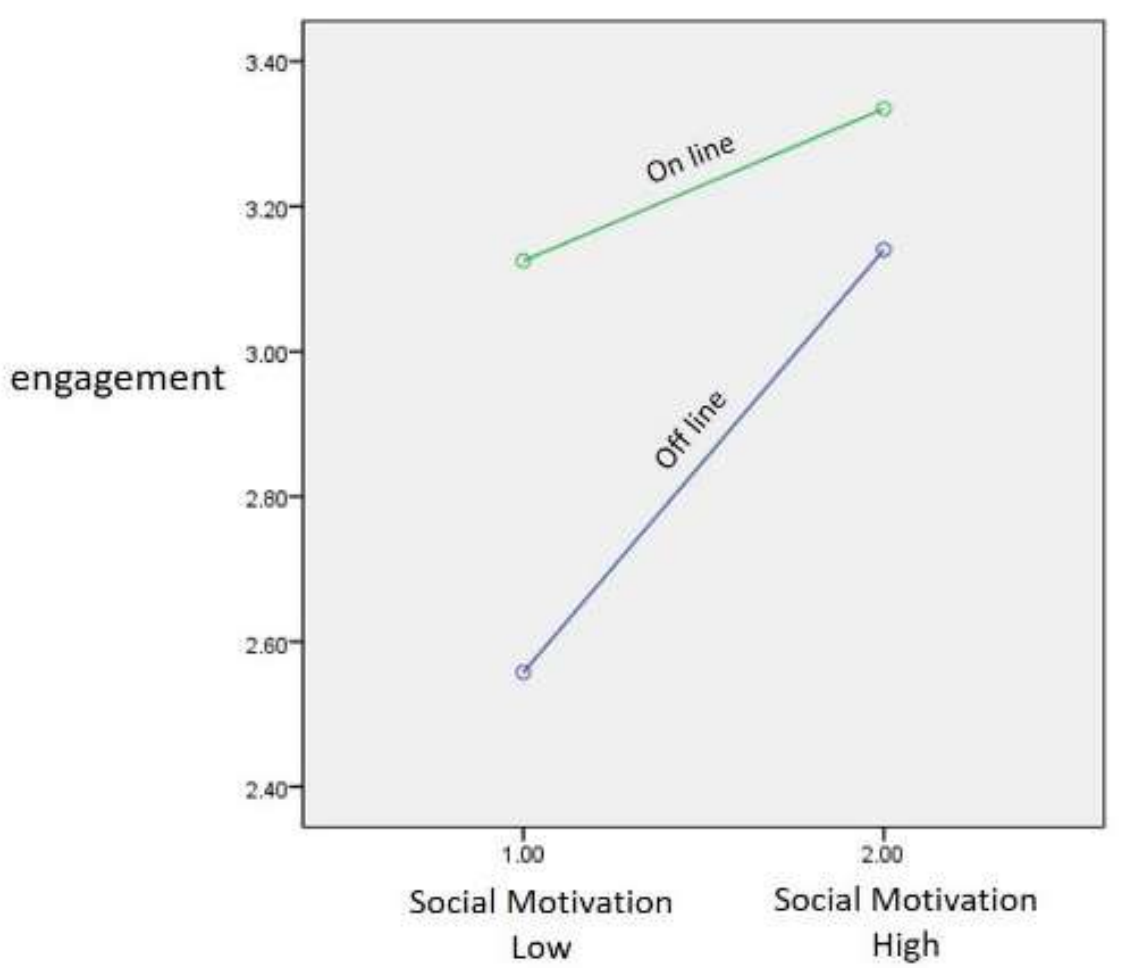

Figure 1. Engagement score according to social motivation by class type 


\section{Conclusion}

The purpose of this study is to investigate the engagement of specific issues to see the differences between groups according to class types by dividing learners' learning motivation into individual motivation and social motivation. As a result, while the interaction between personal motivation and class type is not significant, the interaction between social motivation and class type is significant. The originality of this study is to find out that online education has confirmed the primary effect of increasing engagement on educational subjects rather than offline education. In particular, the group with low social motivation showed greater change than the group with high social motivation, so online education seems to be more effective in the group with low social motivation. These results seem to be able to induce learners' behavioral changes and attitudes as a result of learning by stimulating social motivation rather than personal motivation in order to obtain the effect of online education.

Engagement used in this study is a variable that is used in various ways from traditional media to new media. It can be said that it is most suitable as a variable that measures the complex attitude of consumers who use new and old media in parallel, as it includes all of the preferences, involvement, and interests of individuals. Due to the global pandemic of COVID-19, the transition to full-scale online classes in the educational field has been rapidly made, and the rapid change of class types has made it important to find effective teaching methods. When it is very necessary to think about the content or form of online specialized education, the results of this study provide the following implications.

First, online education can activate individual engagement overall rather than offline education. This is not found in the grouped offline education method, and the result of increasing individual participation, personal recollection, involvement, and interest through personalized online classes is a very meaningful result in the current media environment. In fact, through online education, repetitive learning or participation in classes has increased, and these factors appear to be positive evaluations of classes. Therefore, if the main purpose is to increase engagement in online education, it is expected that a rational education effect evaluation can be performed.

Second, the most meaningful result of this study is that the effectiveness of interaction between social motivation and class type was significant. That is, the group with low social motivation showed a very high increase in engagement through online education than the group with high social motivation, which differentiates it from the previous researches on online education effect. In the previous offline education, the participation of the group with high social motivation was relatively more advantageous than the group with low social motivation, and because the evaluation of classes was made through this, it was practically difficult to expect a class effect for the group with low social motivation. However, it is inferred that the level of interest in specific issues could be increased in the group with low social motivation as online classes were personalized, unlike offline classes, and methods such as repeated listening and speed control were possible according to the level of individual learning motivation. This is to confirm that online education can bring more excellent effects to liberal arts education rather than major education.

Liberal education in most universities begins with a very low interest in students' voluntary participation or subject issues. Therefore, various teaching methods are being mobilized to increase student interest. According to the results, online education seems to be an alternative. The low level of interest of non-majors in specific issues or topics is inevitably low in social motivation as well as personal motivation, but online education can increase the interest of groups with low social motivation. These results have many implications for online education. Compared to offline education, online education has a higher use of media, and the use of a variety of media can increase personal immersion, which shows the possibility of increasing social interest in specific issues. In particular, considering that the class content used in this study is a liberal arts education on a specific issue of unification, the results of this study show that online education can be more effective than offline education.

Unification education in Korea, Republic of. is one of the very important education that has been continuing since the national division. Especially, while unification education centered on majors was dominant in the past, the transition to popular unification education through liberal arts courses has recently been made. The results of this study can suggest the direction of content and formal changes in effective online education. In other words, it is necessary to activate social communication methods such as SNS that can induce more participation in groups with low social motivation in the extremely personal space of online. It is believed that the development of social and interpersonal issues and learning materials will be more efficient in online education than offline.

This study derives the research results according to the liberal arts classes on the subject of unification for college students. Groups were classified based on motivation, but in order to derive more specific results, the level of prior knowledge and involvement of students should be carefully 
classified and measured, and the students' pre- and post-class conditions should be comprehensively investigated through more variables for comparative analysis. Finally, in order to increase the reliability of the research results, it is necessary to clearly prove it through the establishment of a structural model. In addition, for generalization of the research results, it is necessary to repeat the same research in liberal arts courses on different subjects, and to compare it with the major class.

\section{References}

[1] Mitchell, M. (1993). Situational interest: Its multifaceted structure in the secondary school mathemat ics classroom. Journal of educational psychology, 85(3), 424-436.

[2] Geen, R. G., Beatty, W. W., \& Arkin, R. M. (1984). Human motivation: Physiological, behavioral, and soc ial approaches. Allyn \& Bacon.

[3] Higgins, E. T. (2000). Does personality provide unique explanations for behavior? Personality as cros s-person variability in general principles. European Journal of Personality, 14(5), 391-406.

[4] Higgins, E. T. (2006). Value from hedonic experience and engagement. Psychological review, 113(3), 439-460.

[5] Tao (2013). Personality, Motivation, and Behavioral intentions in the experiential consumption of artworks. Social behavior and Personality, 41(9), 1533-1546.

[6] Lawson, R., \& Thyne, M. (2000). Destination avoidance. Reflections on International Tourism: Motivations, Behaviour and Tourist Types, 255-266.

[7] Kotler, P., \& Scheff, J. (1997). Standing room only: Strategies for marketing the performing arts. Harvard Business School Press.

[8] Ephron, E. (2006). Media Planning-From Recency to Engagement. ICFAI Books.

[9] Pintrich, P. R., DeGroot, E. V. (1990). Motivational and self-regulated learning components of classroom academic performance. Journal of Education Psychology. 82(1), 33-40.

[10] Carini, R. M., Kuh, G. D., \& Klein, S. P. (2006). Student engagement and student learning : Testing the linkage. Research in Higher Education, 47(1), 1-32.

[11] Wang, A. (2006). Advertising Engagement: A driver of message involvement on message effects. Journal of Advertising Research, 46(4), 355-368. 